\title{
HIF-prolyl hydroxylase domain proteins (PHDs) in cancer - potential targets for anti-tumor therapy?
}

Diana Gaete ${ }^{1}$, Diego Rodriguez ${ }^{1}$, Deepika Watts ${ }^{1}$, Sundary Sormendi ${ }^{1}$, Triantafyllos Chavakis ${ }^{1}$, Ben Wielockx ${ }^{1, *}$

${ }^{1}$ Institute of Clinical Chemistry and Laboratory Medicine, Technische Universität Dresden, 01307 Dresden, Germany

*Correspondence to: Ben Wielockx, Institute of Clinical Chemistry and Laboratory Medicine, Technische Universität Dresden, Fetscherstrasse 74, 01307 Dresden, Germany, e-mail: Ben.Wielockx@tu-dresden.de - Phone: +49.351 .458 .162 .60$

Keywords: hypoxia, tumor, PHD, HIF 


\section{Abstract}

Solid tumors are typically associated with unbridled proliferation of malignant cells, accompanied by an immature and dysfunctional tumor-associated vascular network. Consequent impairment in transport of nutrients and oxygen eventually leads to a hypoxic environment wherein cells must adapt to survive and overcome these stresses. Hypoxia inducible factors (HIFs) are central transcription factors in the hypoxia response and drive the expression of a vast number of survival genes in cancer cells and in cells in the tumor microenvironment. HIFs are tightly controlled by a class of oxygen sensors, the HIF-prolyl hydroxylase domain proteins (PHDs), which hydroxylate HIFs, thereby marking them for proteasomal degradation. Remarkable and intense research during the past decade has revealed that, contrary to expectations, PHDs are often overexpressed in many tumor types and that inhibition of PHDs can lead to decreased tumor growth, impaired metastasis and diminished tumor-associated immune-tolerance. Therefore, PHDs represent an attractive therapeutic target in cancer research. Multiple PHD inhibitors have been developed that have either been recently accepted in China as erythropoiesis stimulating agents (ESA) or are currently in phase III trials. We review here the function of HIFs and PHDs in cancer and related therapeutic opportunities. 


\section{Introduction}

An expanding tumor mass is characterized by a hypoxic tumor microenvironment because oxygen levels drop as the tumor outgrows the supply capabilities of the surrounding blood vessels. Therefore, hypoxia is a major hallmark of solid tumors. Several studies have shown that tumor biology is significantly affected by cancer-related hypoxia, which includes formation of a dysfunctional and disordered vasculature that is typically seen in fast-growing tumors [1]. Additionally, although extreme hypoxia classically results in cell death in normal cells, this stress can induce changes that enable tumor cells to adapt to and survive in a hypoxic microenvironment. Such a response to deprived oxygen comprises both genomic and transcriptomic changes that may lead to genetic instability, cell cycle arrest, and cell death and differentiation [2]. Eventually, persistent hypoxia exerts a selection pressure that results in the survival of certain tumor cell subpopulations that are capable of growth, invasion, and even metastasis [3-5]. This efficient cellular adaptation to variations in oxygen levels is tightly regulated by the hypoxia-inducible factor (HIF) family of transcription factors, which are heterodimeric proteins composed of an oxygensensitive alpha subunit (mainly HIF $1 \alpha$ and HIF2 $\alpha$ ) and a constitutively expressed beta subunit (HIF $\beta / A R N T)$.

Although HIF1 $\alpha$ and HIF2 $\alpha$ share overlapping target genes, both also regulate a set of unique targets that are implicated in unrelated processes, and interestingly, they may display even opposite effects, as recently shown in endothelial cells [6]. Notably, these hypoxia-dependent, HIF $1 \alpha$ - and HIF2 $\alpha$-induced genes play important roles in regulating different aspects of tumor biology such as angiogenesis [7], survival [8], proliferation [9], immune system resistance [10], tumor cell plasticity [11], invasion and metastasis [12], chemo- and radio-resistance [13,14], pH regulation and metabolism [15], and maintenance of cancer stem cells (CSCs) [16]. Normoxic conditions do not require HIF activity and they are marked for degradation when the HIF $\alpha$ subunits are hydroxylated at two specific proline residues by specific enzymes, i.e., the prolyl-4-hydroxylase domain (PHD) proteins. PHDs can hydroxylate these proline residues on the oxygendependent degradation domain (ODDD) at N- or C-termini (NODDD and CODDD, respectively) of HIF1 $\alpha$ 
and HIF $2 \alpha$, which then serves as a signal for HIF $\alpha$ degradation by the oxygen-dependent von Hippel-Lindau (VHL) via the 26S proteasome proteolytic pathway [17,18]. There are three known PHD isoforms- PHD1, PHD2 and PHD3, which are encoded by EGLN2, EGLN1 and EGLN3, respectively, and they have been shown to selectively hydroxylate HIF $\alpha$ subunits. Under normoxic conditions, PHD1 and PHD2 preferentially target HIF $2 \alpha$ and HIF1 $\alpha$, respectively, while HIF2 $\alpha$ is the preferred substrate of PHD3 under hypoxic conditions $[19,20]$. Due to its association with various physiological and pathological processes, PHD2 is thought to be the main regulator of this hypoxia pathway (previously reviewed by our group in [21]). Mechanistically, when $\mathrm{pO}_{2}$ decreases to levels that inactivate PHDs, HIF1 $\alpha$ and HIF2 $\alpha$ can no longer be hydroxylated, resulting in their accumulation in the cytosol. Subsequent nuclear mobilization enables their dimerization with the HIF $\beta$ subunit and transcription initiation [22,23]. Importantly, regulation of HIF1/2 $\alpha$ by PHDs has been linked to contrasting tumor outcomes (http://www.cbioportal.org/). In this review, we focus on the impact of PHDs and HIFs in cancer and discuss current and potential therapeutic approaches.

Vascularization and hypoxia in the tumor and its microenvironment

The tumor microenvironment (TME) is an ensemble of cancer cells, cancer-associated fibroblasts (CAFs) and immune cells, including regulatory $\mathrm{T}$ (Treg) cells and tumor associated myeloid cells. The tumor microenvironment is hypoxic due to the presence of dysfunctional tumor vasculature. This lack of oxygen dampens PHD-dependent negative regulation of the HIFs, and the consequent stabilization of these transcription factors launches an array of processes that facilitate cell survival (Figure 1). Within the TME, cell adaptation and selective pressures such as hypoxia, acidosis [24], competition for space and nutrients [25,26], cooperation and predation by the immune system, $[27,28]$ result in the 'survival of the fittest' wherein those tumor cells that are capable of adapting to such harsh conditions maintain their proliferation and even disseminate $[29,30]$. 


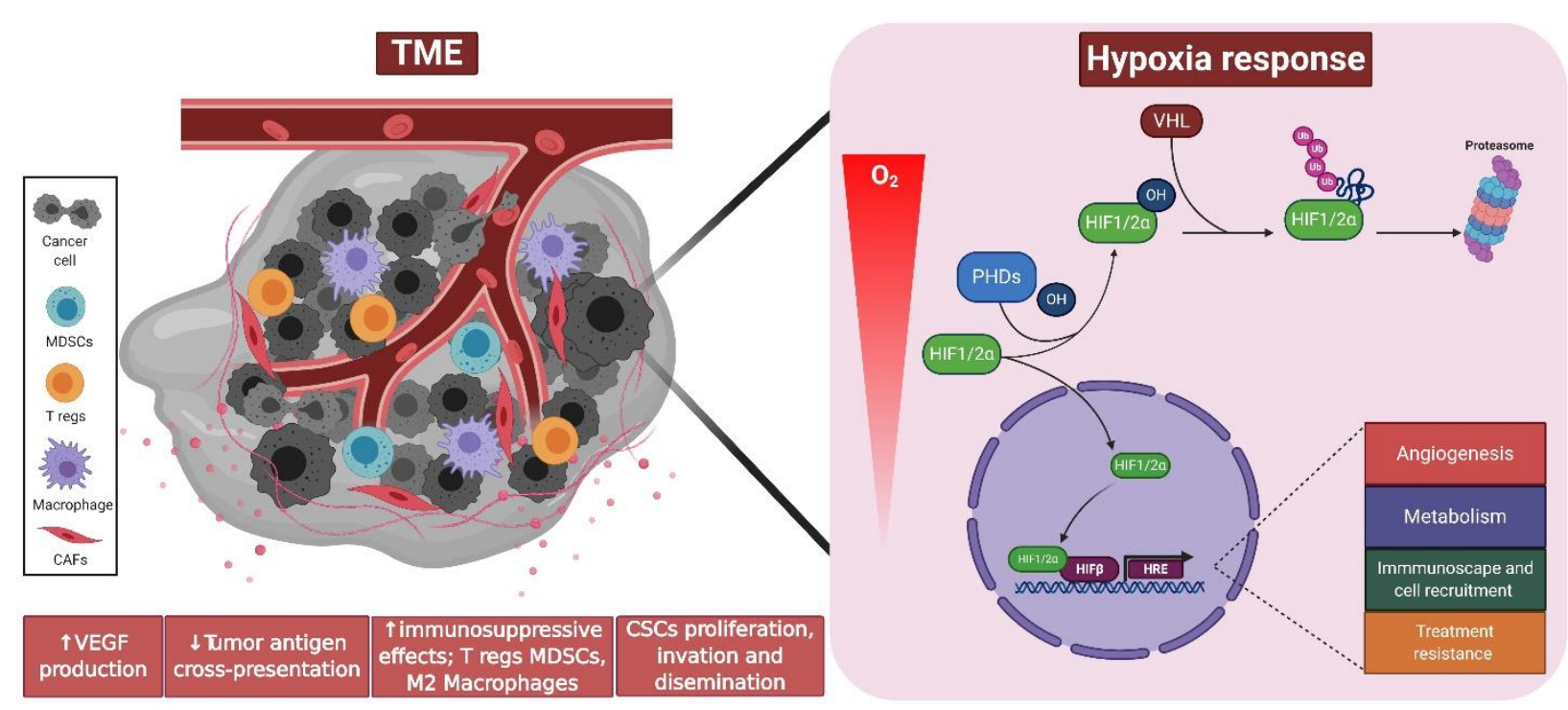

Figure 1: The hypoxic TME favors HIF-dependent transcriptional responses in cancer and/or stromal cells. "Survival of the fittest" leads to excessive proliferation and dissemination of the more aggressive malignant cells capable of survival under the harshest conditions. For more details, please see text. Developed in Biorender.com

Further, in solid tumors, the dysfunctional sprouting of new vessels [31] and inefficient vascular mimicry [32] favor tumor progression, tumor cell motility, invasion, and metastasis [33,34]. Of all these aforementioned processes, hypoxia remains a central mechanism that aids tumorigenesis, progression, and resistance to chemo- and radio-therapy [35-38]. Zhou and collaborators have investigated the role of PHDs in vascularization using the PHD inhibitor roxadustat (described in detail later in this review), which promoted endothelial cell tube formation in an in vitro angiogenesis model. Interestingly, as greater HIF $1 \alpha$ stability and VEGF activation led to significantly enhanced vascular coverage in a subcutaneous tissue engineering chamber model, the authors reasoned that inhibition of PHDs (and consequent HIF stabilization) would result in a potentially pro-angiogenic milieu for tissue remodeling [39]. In contrast, vascular disarray represents a major setback in cancer treatment as it impairs delivery of drugs or therapeutics [40-42]. Interestingly, in a $\mathrm{PHD}^{+/-}$mouse model, Mazzone and colleagues observed normalization of tumor vasculature due to tightened junctions between endothelial cells, and subsequent metastasis reduction [43]. Thus, involvement of PHD2 in vascular normalization represents a potential therapeutic link wherein PHDs can be targeted to prevent tumor dissemination and metastasis. 


\section{Tumor hypoxia and metabolism}

Rapid growth of tumor cells with concomitant ineffective vascularization lead to an unequal distribution of both oxygen and nutrients, and this added selective pressure promotes an evolutionary metabolic shift in malignant cells to meet the needs of tumor development. A major determinant of cell survival in this toxic environment is the ability to switch from an oxidative metabolism to a glycolytic one, and tolerate the resultant increase in the level of acidosis due to lactate production (reviewed in [44]). As mentioned previously, stabilization of HIF $1 \alpha$ plays a major role in the activation of genes needed to increase angiogenesis, glycolytic metabolism, $\mathrm{pH}$ regulation, autophagy, migration, and invasion, and serves to further increase resistance to radiotherapy and chemotherapy [45,46]. In malignant cells, a metabolic shift to fulfil the demands of rapid and uncontrolled growth includes reducing the synthesis of acetyl-CoA from glucose, downregulating fatty acid synthesis [47] and controlling $\beta$-oxidation using adipocyte-derived lipids to reduce cell dependence on de novo lipogenesis [48]. Moreover, the switch towards lactate generation from glucose, even under aerobic conditions (referred to as the Warburg effect and reviewed in depth in [49]), is an adaptation to intermittent hypoxia in pre-malignant lesions [50]. Interestingly, accruing evidence shows that tumor cells remain heterogeneous within the same neoplastic mass (intra-tumor heterogeneity), which also contributes to treatment resistance and cancer progression [51,52]. Additionally, the effects of the TME are beneficial for the neoplastic cells as they promote cooperation among tumor stroma cells to favor tumor progression. In that respect, CAFs promote tumor growth and invasion, and they are susceptible to a shift towards a catabolic metabolism because of the hypoxic TME [53]. Zhang et al. have demonstrated that CAFs are predisposed to switch from oxidative phosphorylation to aerobic glycolysis in a HIF1 $\alpha$ dependent manner to ensure the tumor-promoting effects of CAFs during hypoxia. Reduced isocitrate dehydrogenase 3 complex (IDH3a), accompanied by a decrease in $\alpha$-ketoglutarate $(\alpha-\mathrm{KG})$, affects the ratio of fumarate and succinate, resulting in HIF1 $\alpha$ protein destabilization through PHD2 activity. In contrast, overexpression of IDH3a impedes the fibroblasts-to-CAFs transformation [53]. Taken together, PHDs appear to play a negative role in the development of CAFs and their recruitment by the TME. Other cell 
types present in the TME, such as immune cells (Reviewed in [54]), are also susceptible to metabolic derangement to adapt to the harsh conditions seen in the tumor.

\section{Tumor hypoxia promotes recruitment of pro-tumoral immune cells}

The TME actively releases pro inflammatory cytokines, such as TNF, IL-1 and GM-CSF, and cancer cells add IL-6/8 to the mix, further attracting immune cells [55]. Additionally, hypoxia can enhance or reduce, as the case may be, the infiltration of a substantial number of immunosuppressive cells, such as tumor-associated macrophages (TAMs), myeloid-derived suppressor cells (MDSCs), and T-regulatory cells (Treg), as described below.

TAMs have been linked to enhanced tumor vascularization, greater invasion and metastasis, immune tolerance, and tumor chemo-resistance [56], and lower oxygen concentrations in tumors have been revealed as the mechanism underlying both monocyte recruitment and their subsequent differentiation into a pro-tumoral M2 or TAM phenotype [57,58], which is in contrast to the pro-inflammatory M1 macrophage. It has been proposed that hypoxia can dictate the metabolic profiles associated with M1- and M2-polarised cells. Specifically, while the M1 macrophages produce high levels of iNOS [59], activate HIF1 $\alpha$, and thereby favor glycolysis [60], the M2 phenotype is essentially anti-inflammatory, pro-metastatic [61], and produces high levels of Arginase I (Arg1) [59,62] by activating HIF2 $\alpha$ [63]. Further, M2 macrophages mainly produce ATP through the oxidative TCA cycle linked to oxidative phosphorylation (OXPHOS) and rely on fatty acid oxidation (or $\beta$-oxidation) and glutamine metabolism, which fuels the TCA cycle [60]. For this reason, hypoxia-induced TAMs polarization is considered a major setback in cancer therapy.

The involvement of PHDs in TAM accumulation, polarization and survival has been suggested, and in a recent study, Wang et al have demonstrated that PHD2 overexpression in murine colon cancer xenografts (CT26 and MC38) decreased tumor burden, M2-TAM infiltration, and levels of inflammatory cytokines, namely, TNF, G- CSF, IL-8, IL-4, IL-1 $\beta$, and IL-6 [64]. Similarly, another study that used bone 
marrow derived macrophages (BMDMs) isolated from mice deficient in PHD2 in myeloid cells has shown a role for PHD2 in macrophage polarization. Although HIF1 $\alpha$ and HIF2 $\alpha$ are known to modulate macrophage polarization, the PHD2 knockout (cKO) macrophages in that study did not show any polarization. Moreover, the $\mathrm{O}_{2}$ consumption rate (OCR) of the BMDMs was significantly reduced, whilst showing an increased level of extracellular acidic rate (ECAR). These observations underscore the occurrence of a metabolic shift that resulted in lower phagocytosis and migration of the PHD2 cKO macrophages [65].

Two major categories of myeloid-derived suppressor cells (MDSCs) have been identified in mice, viz., polymorphonuclear CD11b $\mathrm{Ly}^{+} \mathrm{G}^{+} \mathrm{Ly}_{6} \mathrm{C}^{\mathrm{lo}}$ (PMN-MDSCs) and monocytic CD11b+Ly6G-Ly6C ${ }^{\text {hi }}$ (MMDSCs). There is substantial functional overlap of PMN-MDSCs with tumor-associated neutrophils (TAN)-2 promoting tumor growth [66,67], as opposed to TAN-1 that have anti-tumor activities [68,69]. MDSCs are known to exert very fundamental immunosuppressive functions, such as inhibition of T cell cytotoxicity [70,71], but tumor hypoxia plays a pivotal role in MDSC recruitment [72]. Moreover, HIF1 $\alpha$ promotes the expression and regulation of Arg1 and iNOS [73-75], and the Wang et al study also documented an anti-inflammatory effect of PHD2, apart from revealing its involvement in the recruitment of MDSCs during tumor progression [64]. Specifically, overexpression of PHD2 impaired MDSC recruitment due to a decrease in NF-אB activity that resulted in lower TNF and G-CSF expression, which are crucial cytokines for MDSC mobilization [76,77] from colon cancer cells [64].

Treg-mediated immunosuppression in cancer enables malignant cells to escape detection by host immune system surveillance mechanisms and several reports have confirmed Treg accumulation within the TME [78-80] (reviewed in depth in [81]). Moreover, a hypoxic environment increases HIF1 $\alpha$-induced expression of the distinct Treg marker and master regulator forkhead box P3 (Foxp3) [82,83]. In contrast, PHD2 has been recently reported to modulate immunosuppressive capabilities of the Tregs. For example, Yamamoto and colleagues have reported that silencing of PHD2 using doxycycline (DOX)-induced expression of shRNAs for PHD2 stabilized HIF2 $\alpha$ in the hematopoietic compartment, which resulted in the 
loss of immunosuppressive function in Tregs. Moreover, the Treg population associated with a naïve phenotype (CD44loCD62Lhi) was significantly reduced, while the effector memory cell (CD44hiCD62Llo) population was increased [84]. This clear connection between PHD2 and Treg function warrants further studies that explore the role of PHD2 in TME-associated immunosuppression and targeting of PHD2 could potentially lead to loss of tumor-induced immune tolerance, and hence, more efficient immunosurveillance. Additionally, PHD3 is crucial for the development of Tregs, as anti-PHD3 siRNA downregulated Foxp3 and upregulated HIF1 $\alpha$ expression, leading to development of Th17 cells [55].

Tumor hypoxia and treatment resistance: Cancer stem cells (CSC) and the epithelial-tomesenchymal transition (EMT)

Of the many features of CSCs, the most fundamental are enhanced DNA-repair mechanisms and induction of a quiescent state [85]. As conventional therapies primarily target highly dividing cells, quiescent CSCs represent a dangerous subpopulation that remains undetected and, more importantly, unaffected. Furthermore, inefficient oxygen distribution throughout the tumor allows undifferentiated cells to populate the hypoxic region and there is evidence that CSCs can metabolically adapt to using lactate as their energy source during metastatic colonization (Warburg effect) in a HIF1-dependent manner [86-88]. As, both HIF1 and HIF2 are highly expressed in CSCs [89], the use of HIF inhibitors, in combination with current therapies, can be developed into an effective counter measure to reduce resistance.

Glioblastoma (GBM) is an aggressive but very common brain tumor. The fast-growing nature of GBMs contributes to the development of an acute intratumoral hypoxic microenvironment, resulting in heterogeneity among malignant cells [90,91]. The glioma stem-like cells (GSCs) certainly benefit from the hypoxic environment as they acquire multipotency and self-renewal capacity, both of which are linked to treatment-resistance and tumor recurrence [92-94]. Not surprisingly, HIF $1 \alpha$ expression is increased in both GSCs and non-GSCs, and it has been reported that GSCs promote their tumorigenic capacity and expansion in a HIF1 $\alpha$-dependent manner [95]. Thus, hypoxia-mediated expansion of GSCs has become a potential 
target for glioblastoma therapy. Additionally, HIF $2 \alpha$ activity has been related to GSCs and tumor progression. A compelling analysis of angiogenesis-related factors in 50 human GBM samples concluded that there was a significant abundance of HIF2 $\alpha$ over HIF1 $\alpha$ [96]. Furthermore, several studies have demonstrated that HIF $2 \alpha$ is preferentially expressed within a tumor stem cell subpopulation, stimulated by CD44 and that it drives tumor differentiation [95,97,98]. Mechanistically, in vivo studies have shown that the intracellular domain (ICD) of CD44 binds to and activates HIF2 $\alpha$, but not HIF1 $\alpha$, in an oxygenindependent manner [98].

A factor that contributes to CSC development is epithelial-to-mesenchymal transition (EMT), which constitutes a highly coordinated program wherein epithelial cell markers are suppressed while mesenchymal markers are upregulated. This program does not work as a simple on/off switch; in fact, EMT markers manifest in varying degrees and cells can also regress to a more epithelial state. Under nonpathological conditions, the EMT program is required for tissue morphogenesis during embryonic development and is coordinated by multiple transcription factors (EMT-TF), including Slug, Snail, Twist, Zeb1, and Zeb2/SIP1. Each of these EMT-TFs is capable of repressing E-cadherin expression, leading to changes in gene expression, including that of mesenchymal markers, and increasing cellular motility. Moreover, cancer cells that have undergone EMT display CD44 ${ }^{\text {high }} / \mathrm{CD} 24^{\text {low }}$ expression and are characterized by many of the properties seen in self-renewing stem cells. The final outcome of these changes are related to development of resistance to anti-tumor therapies and initiation of tumor growth in secondary organs [99-101].

The EMT program can be triggered by a variety of mechanisms, including intra-tumoral hypoxia [102]. HIF1 $\alpha$ can particularly induce EMT by upregulating the expression of EMT-TFs in several types of cancers, including lung, colorectal and head and neck cancers [103-107]. Besides hypoxia, adaptive changes in cancer cells following therapy (such as the Warburg effect) [108], as well as several growth factors, can trigger EMT programs, with the relevant factors being transforming growth factor beta (TGF- $\beta$ ), receptor tyrosine kinase (RTK) ligands, epidermal growth factor (EGF), insulin growth factor (IGF), hepatocyte 
growth factor (HGF), fibroblast growth factor (FGF), and platelet-derived growth factor (PGDF) $[99,100]$. The hypoxia pathway regulates several of these growth factors as well [21,109,110]. Additionally, microRNAs (miRNAs) regulate EMT and the key candidates include the miRNA-200 family, miRNA-205, miRNA-155, let-7, and miRNA-34a [99,111]. Like the growth factors, some miRNAs may be regulated by hypoxia and/or affect the hypoxic response, e.g., miRNA-155, let-7, and miRNA-34a [111-113]. Increasing expression of the microRNA-200 family and Let-7a is used therapeutically, and a MIR34a mimic has been shown to have anti-tumor activities; however, clinical trials were terminated due to immune-related adverse effects $[114,115]$

As indicated above, targeting CSCs remains challenging because cells that have undergone at least one partial EMT program exhibit intensified resistance to apoptosis or an ability to force out cytotoxic drugs [100]. Therapies that target EMT aim to halt CSC production to hamper metastasis and cancer progression and have focused on three approaches: 1) targeting EMT-inducing signals, 2) reversing EMT, and 3) killing cells in an EMT-like state. A few clinical trials testing the efficacy of suppressing the EMT program are underway, and while Notch or HIF1 $\alpha$ inhibitors have been proposed to work by targeting stemness or the EMT, TGF $\beta$ inhibitors have been used to target tumor cells that have activated versions of the EMT program, and the WNT/FZD pathway is targeted for tumor dedifferentiation [100,116]. As EMT is induced by HIF1 $\alpha$ and therapy targets are frequently inhibited, PHDs have not been explored as therapy targets.

\section{The hypoxia pathway in PCC/PGLs and potential therapies}

The peripheral nervous system is composed of different types of cells located throughout the body and they serve as the origin of many kinds of benign and malignant tumors. Examples include neural crestderived neuro-endocrine tumors (NETs), such as paragangliomas (PGLs) that originate from extramedullary paraganglia, as well as pheochromocytomas (PCCs), which are endocrine tumors arising 
from chromaffin cells located in the adrenal medulla [117,118]. Neuroendocrine properties of these tumors lead to excessive production of catecholamines such as dopamine, norepinephrine and epinephrine [119].

PCCs and PGLs are currently subdivided into two major clusters based on underlying mutations in the predisposing genes: the pseudohypoxia-associated cluster 1 and the kinase signaling-associated cluster 2; however, a potential third cluster associated with WNT-signaling has also been recently described $[120,121]$. Cluster 1 includes tumors associated with mutations in $V H L$, succinate dehydrogenase (SDHx) genes or $P H D 2$, which lead to stabilization of HIF proteins, especially HIF $2 \alpha$, thereby creating a pseudohypoxic state [119,122]. Additionally, gain-of-function mutations in exon 9 and 12 of HIF2 $\alpha$ have been added to the list of genes associated with PCCs and PGLs $[123,124]$. These mutations in HIF2 $\alpha$ result in defective proline residues at the hydroxylation sites, resulting in reduced degradation, and hence, their stabilization. As mentioned before, activation of the HIF pathway also facilitates the Warburg effect, which favors tumor growth by overexpressing genes involved in the glucose metabolism [125]. Another important factor that is upregulated in cluster 1 associated tumors, specifically in relation to SDH and VHL mutations, is mir-210. Its expression is induced by HIF $1 \alpha$ and it is believed to regulate the expression and function of tumor-associated genes [126].

Additionally, HIF2 $\alpha$ stabilization due to mutations in any of the above-mentioned genes in cluster 1 PCCs and PGLs leads to diminished transcription of PNMT, which is the central enzyme that regulates the conversion of norepinephrine to epinephrine. Even though a majority of these tumors are benign, 15$20 \%$ metastasize; however, in the absence of markers to distinguish between the two, development of appropriate treatment strategies is essential. As it is well established that HIF2 $\alpha$ is a major driver of PCCs and PGLs, therapeutic targeting of HIF2 $\alpha$ is a potential treatment strategy. However, targeting using small molecules only came to light once the structure of the HIF $2 \alpha / \mathrm{HIF} \beta$ dimer was resolved by crystallography, and this led to the identification of a large protein cavity in the HIF2 $\alpha$ PAS-B domain. Both in vitro and in vivo models of these rare neuroendocrine tumors showed inhibition of tumors by treatment with HIF2 $\alpha$ inhibitors [127]. Therefore, HIF2 $\alpha$-specific inhibitors represent a successful method of targeting the core of 
PCCs and PGLs. Nevertheless, further research and clinical trials are necessary to establish any potential treatment strategy using HIF2 $\alpha$ inhibitors in combination with other existing anti-tumor therapies [128].

CSCs have also been suggested as potential tumor therapy targets in PCC and PGL [129], and it is not surprising that cancer cells from cluster 1 pseudohypoxia-related tumors express CSC markers [130]. Targeting CSCs via surface markers or by inhibiting developmental stem cell pathways has been used in the clinic for the treatment of other tumors such as in the lung [131] and given their promising outcome, CSC targeting might prove useful, even in PCCs and PGLs.

\section{The PHD-HIF axis as a central regulator of tumor development}

Our group has previously reported a clear pattern of pro- and anti-tumor effects of PHDs among human cancer types [21,132]. These differences point to the presence of a case-by-case scenario, where the individual PHDs can be either beneficial or detrimental to tumor growth, and thus, potentially define future therapy decisions. Interestingly, more cases have been reported that show over-expressing of PHDs in tumor tissue versus healthy neighboring tissue, with few exceptions [21]. In colorectal cancer (CRC), PHD2 has been associated with a protective role. Through its regulatory subunit B55 $\alpha$, PP2A dephosphorylates PHD2 at Ser125, rendering it non-functional, and consequent accumulation of HIF1 $\alpha$ leads to CRC cell survival in hypoxia through autophagy. Targeting B55 $\alpha$ impairs CRC neoplastic growth in vitro and in mice in a PHD2-dependent manner [133]. Similarly, another study in breast carcinoma xenografts reported that, when subjected to a glycolysis inhibitor 2-DG (2-deoxy-glucose) to mimic glucose starvation, tumors that lacked PHD2 showed greater resistance to treatment compared to controls, strongly suggesting that PHD2mediated B55 $\alpha$ degradation facilitates breast cancer cell death in response to chronic glucose deprivation [134]. Alongside the evidence that PHD2 overexpression can be favorable in restricting tumor development,

contrastingly, silencing of PHD2 reduces tumor growth and survival in many studies. As shown previously by our group, ablation of PHD2 in different murine tumor cell lines such as Lewis lung carcinoma [LLC] model, B16 melanoma, and LM8 osteosarcoma, led to a significant increase in tumor vasculature, followed by a significant reduction in tumor growth due to enhanced MMP activity and TGF- $\beta$ release within the 
TME $[132,135]$. Another study showed that PHD2 knockdown in MDA-MB-231 xenografts resulted in significantly lower epidermal growth factor receptor (EGFR) expression levels compared to controls. Nonetheless, the authors claimed that EGFR downregulation was independent of the influence of HIF1 $\alpha$ or HIF2 $\alpha$ [136]. The pro-oncogenic adaptor protein, CIN85 has been recently identified as an indirect regulator of PHD2 activity. Kozlova and colleagues have shown that disruption of the CIN85-PHD2 interaction using CRISPR/Cas9 editing not only led to lower levels of HIF1 $\alpha$ and HIF2 $\alpha$, but also to significantly impaired tumor growth and migration in a breast carcinoma model (MDA-MB-231) [137]. The group of Vidimar explored the redox properties of a ruthenium organometallic compound (RDC11) that directly interacts with PHD2 and showed that RDC11 reduced HIF1 $\alpha$ protein level and function by promoting the enzymatic activity of PHD2. Upon RDC11 administration in human colorectal adenocarcinoma (HCT116 cell line) in vivo, levels of HIF1 $\alpha$ were significantly reduced and, consequently, VEGF levels and angiogenesis, leading to a reduction in tumor size [138]. Using a human LM2 xenograft model, Koyama et al [139] investigated subsequent tumor vessel normalization after PHD inhibition using DMOG and showed that tumor vessel normalization was accompanied by angiogenesis, which rescued sensitivity to chemotherapy [139].

Remarkably, although PHD3 also displays pro-tumoral activity, a number of human- and mouseassociated tumors show reduced amounts of PHD3 compared to adjacent healthy tissue. In a lung carcinoma model, PHD3 also exerted tumor-suppressive activity, apart from regulating EMT, metastasis, and resistance to therapy. PHD3 knockdown in other cell lines (A549 and H1299 cells) enhanced pulmonary metastasis in a HIF-dependent manner that involved upregulation of TGF $\alpha$, an EGFR ligand [140]. In gastric cancer, cell migration and invasion were significantly higher in PHD3-silenced tumor cells than controls, and both HIF1 and VEGF showed greater expression [141]. In mouse LM8 osteosarcoma, we showed that PHD3 is a tumor suppressor as silencing of this oxygen sensor led to enhanced tumor growth and dramatically changed vessel morphology that was directly related to significantly activated platelet-derived growth factor (PDGF)-C signaling in the vasculature of PHD3 knockdown tumors [142]. Thus, the impact of the PHDs in tumor progression is diverse and cell-dependent, i.e., tumor cell vs. TME. Therefore, an 
effective therapeutic approach will require genomic profiling of tumors to identify the correct treatment needs for each patient [143].

Pharmacological inhibition of PHDs and insights for cancer treatments.

In recent years, PHD inhibitors (PHDi) have been developed as erythropoiesis stimulating agents (ESA) for use in patients suffering from anemia that is often associated with kidney disorders. Pharmacological inhibition of PHDs leads to HIF $\alpha$ protein stabilization, including HIF2 $\alpha$ in EPO producing cells (EPCs), which results in enhanced EPO production, predominantly in the kidney [144]. This hormone then translocates to the bone marrow where it regulates survival and differentiation of erythroid progenitors to stimulate erythrocyte production. Of the drugs used for HIF-PHD inhibition, data on several relate to cancer scenarios $[145,146]$.

Table 1. Prominent PHDi used in recent cancer research studies

\begin{tabular}{|l|l|l|}
\hline PHDi & Molecular inhibition & Selected studies in cancer models \\
\hline Roxadustat & All HIF-PHDs interactions & $\begin{array}{l}\text { - Increased erythropoiesis in MMTV-Neu but no } \\
\text { differences in tumor development [147]. } \\
\text { - Tumor vessel normalization in mouse LLC tumor, } \\
\text { reduced growth [146,148] and sensitivity to } \\
\text { chemotherapy [139]. }\end{array}$ \\
\hline Vadadustat & PHD3>PHD2>PHD1 & $\begin{array}{l}\text { - No increased plasma VEGF in patients [149] and } \\
\text { upregulates HIF2 } 2 \text { > HIF1 }[145]\end{array}$ \\
& & $\begin{array}{l}\text { - Vessel normalization and reduced tumor growth, but } \\
\text { enhanced expression of angiogenesis markers }>\text { Rox., } \\
\text { Dap. and Mol [148]. }\end{array}$ \\
\hline Daprodustat & PHD1>PHD3>PHD2 & $\begin{array}{l}\text { - High doses of drugs did not show carcinogenic } \\
\text { potential in vivo [150]. } \\
- \text { Reduced tumor growth, vascularization and } \\
\text { diminished hypoxic regions [146]. }\end{array}$ \\
\hline Molidustad & PHD2 >PHD3/PHD1 & $\begin{array}{l}\text { - In vitro reduced tumor viability. } \\
- \text { - In vivo impaired tumor growth without altering } \\
\text { angiogenesis in an MDA-MB-231 [151], but with } \\
\text { enhanced normalization in LLC tumors[146] }\end{array}$ \\
\hline
\end{tabular}


1. Roxadustat (FG-4592) is a 2-OG analog and was developed as an inhibitor of HIF-PHDs by FibroGen, AstraZeneca, and Astellas Pharma [145]. Seeley and colleagues studied its implications in cancer progression and found that, in MMTV-Neu ${ }^{\text {ndl }}-$ YD5 (NeuYD) mice, which are a model of spontaneous mammary tumor development that are sensitive to VEGF, oral application of Roxadustat yielded no differences in tumor development compared to mock treated MMTV mice [152], confirming that, despite HIF stabilization translating to increased erythropoiesis, the compound has no tumor promoting effects in vivo. This result was later challenged by Koyama et al [139], who compared DMOG and Roxadustat as PHD inhibitors in LLC tumor models and showed clear tumor vessel normalization and rescue of chemotherapy sensitivity in tumor-bearing mice challenged with the compounds [139,146]. A very detrimental effect to consider when HIFs are activated is the increase in glucose uptake and its consumption during glycolysis, which eventually results in enhanced glycogen storage [153]. This allows cells to survive extreme hypoxic conditions, which, during a neoplastic event, can eventually drive adaptation of malignant cells towards cancer progression, invasion, and metastasis [154]. However, whether these effects could potentially favor tumor progression has not yet been studied. Furthermore, Roxadustat can also inhibit tumor growth of macrophage-abundant tumors by facilitating the phagocytic function of Ly6C $\mathrm{C}^{\text {lo }}$ tumorinfiltrating macrophages, which, at least in part, contribute to vessel normalization [148].

2. Vadadustat [149], developed by Akebia Therapeutics, stabilizes both HIF1 $\alpha$ and HIF2 $\alpha$ and has the potential to inhibit all PHD isoforms but with a preference for PHD3 [145]. One of the main concerns with HIF stabilization by PHDs inhibition with Vadadustat is the risk of facilitating tumor progression due to angiogenesis, secondary to increased VEGF expression [155]. Pergola and collaborators have tested this hypothesis and have reported that levels of VEGF in plasma were not affected after Vadadustat treatment in a phase $2 \mathrm{~b}$ clinical study [149]. Further, a recent study by Nishide and colleagues confirmed this in a mouse model of cancer and also showed that Vadadustat induces tumor normalization and reduces hypoxic regions within tumor tissue. However, when compared to other PHD inhibitors tested simultaneously, these 
tumors showed enhanced expression of other angiogenesis markers like Notchl, eNOS and Heyl, and a mild increase in pro-inflammatory markers [146].

3. Daprodustat [156], developed by GlaxoSmithKline, preferentially inhibits PHD1 and PHD3 [145] and both HIF $1 \alpha$ and HIF $2 \alpha$ isoforms stabilize upon treatment, attesting to its efficacy in activating the hypoxia pathway. Importantly, no carcinogenicity potential was detected for this compound even at high pharmacological doses [150]. Daprodustat was also effective in a mouse LLC model as it resulted in better normalization of the tumor vessels with enhanced pericyte coverage that was linked to diminished presence of angiogenic factors. Moreover, tumor growth was significantly reduced compared to untreated tumors [146].

4. Molidustat [157], developed by Bayer, has a preferential sensitivity for PHD2 [145]. In a report by Nishide et al., this inhibitor also diminished LLC tumor growth that was linked to enhanced blood vessel maturation and an increase in their functionality [146]. Furthermore, Molidustat has been tested in combination with the proliferation inhibitor, gemcitabine, in a mouse model of breast cancer (MDA-MB-231) [158]. In vitro, a dramatic reduction in cell viability was shown in comparison to control, PHD inhibitor alone, or gemcitabine alone. Although the authors reported an increase in VEGF, both in gene expression and protein release into the culture media, it resulted in no significant changes in angiogenesis, other than dramatic anticancer effects in vivo [151].

\section{Conclusions}

This review explored current advances in the biology of PHD enzymes and their association with cancer progression and therapy. The involvement of PHDs in tumor development in many cases may appear paradoxical because, while on the one hand there is evidence showing that PHDs can be detrimental for hypoxia adaptation and cancer progression, the use of PHD inhibitors leads to lower tumor growth and metastasis by diminishing immune tolerance and increasing tumor vessel normalization. Moreover, recent evidence advocates for the use of combination therapies, including pharmacological targeting of PHDs, to 
ensure proper targeting of the individual insults generated by malignant cells. More research is required to obtain a better understanding of the complex mechanisms underlying the effects of hypoxia pathway proteins (i.e., HIFs and PHDs) that are involved in many different types of cancers and pathologies.

Author Contributions: D.G., D.R., D.W., wrote the manuscript; T.C., S.S. and B.W. contributed to the discussion and edited the manuscript.

Funding: This work was supported by grants from the DFG (German Research Foundation) within the CRC/Transregio 205/1, Project No. 314061271-TRR205, “The Adrenal: Central Relay in Health and Disease“(A02) to T.C. And B.W.; DFG grants WI3291/5-1 and 12-1 to B.W. This work was also supported by the DFG priority program $\mu$ BONE 2084 (to B.W.) and the CRC/Transregio 127 to T.C.. B.W. was further supported by the DFG Heisenberg program (WI3291/13-1).

Conflicts of Interest: The authors declare that no relevant conflicts of interest exist.

\section{References}

1. Welch, W.J.; Palm, F.; Bruley, D.F.; Harrison, D.K. Erratum to: Oxygen Transport to Tissue XXXIV. Adv Exp Med Biol 2013, 765, E1-E2, doi:10.1007/978-1-4614-4989-8_53.

2. $\quad$ Al Tameemi, W.; Dale, T.P.; Al-Jumaily, R.M.K.; Forsyth, N.R. Hypoxia-Modified Cancer Cell Metabolism. Front Cell Dev Biol 2019, 7, 4, doi:10.3389/fcell.2019.00004.

3. Tsai, Y.P.; Wu, K.J. Hypoxia-regulated target genes implicated in tumor metastasis. J Biomed Sci 2012, 19, 102, doi:10.1186/1423-0127-19-102.

4. Lungu, G.F.; Li, M.L.; Xie, X.; Wang, L.V.; Stoica, G. In vivo imaging and characterization of hypoxiainduced neovascularization and tumor invasion. Int J Oncol 2007, 30, 45-54.

5. Vaupel, P.; Harrison, L. Tumor hypoxia: causative factors, compensatory mechanisms, and cellular response. Oncologist 2004, 9 Suppl 5, 4-9, doi:10.1634/theoncologist.9-90005-4.

6. Downes, N.L.; Laham-Karam, N.; Kaikkonen, M.U.; Yla-Herttuala, S. Differential but Complementary HIF1alpha and HIF2alpha Transcriptional Regulation. Mol Ther 2018, 26, 1735-1745, doi:10.1016/j.ymthe.2018.05.004.

7. Krock, B.L.; Skuli, N.; Simon, M.C. Hypoxia-induced angiogenesis: good and evil. Genes Cancer 2011, 2, 1117-1133, doi:10.1177/1947601911423654.

8. Chen, S.; Sang, N. Hypoxia-Inducible Factor-1: A Critical Player in the Survival Strategy of Stressed Cells. Journal of cellular biochemistry 2016, 117, 267-278, doi:10.1002/jcb.25283.

9. Hubbi, M.E.; Semenza, G.L. Regulation of cell proliferation by hypoxia-inducible factors. Am J Physiol Cell Physiol 2015, 309, C775-782, doi:10.1152/ajpcell.00279.2015. 
10. Barsoum, I.B.; Smallwood, C.A.; Siemens, D.R.; Graham, C.H. A mechanism of hypoxia-mediated escape from adaptive immunity in cancer cells. Cancer Res 2014, 74, 665-674, doi:10.1158/0008-5472.CAN-130992.

11. Terry, S.; Buart, S.; Chouaib, S. Hypoxic Stress-Induced Tumor and Immune Plasticity, Suppression, and Impact on Tumor Heterogeneity. Front Immunol 2017, 8, 1625, doi:10.3389/fimmu.2017.01625.

12. Zhong, H.; De Marzo, A.M.; Laughner, E.; Lim, M.; Hilton, D.A.; Zagzag, D.; Buechler, P.; Isaacs, W.B.; Semenza, G.L.; Simons, J.W. Overexpression of hypoxia-inducible factor 1alpha in common human cancers and their metastases. Cancer Res 1999, 59, 5830-5835.

13. Rohwer, N.; Cramer, T. Hypoxia-mediated drug resistance: novel insights on the functional interaction of HIFs and cell death pathways. Drug Resist Updat 2011, 14, 191-201, doi:10.1016/j.drup.2011.03.001.

14. Moeller, B.J.; Cao, Y.; Li, C.Y.; Dewhirst, M.W. Radiation activates HIF-1 to regulate vascular radiosensitivity in tumors: role of reoxygenation, free radicals, and stress granules. Cancer Cell 2004, 5, 429441, doi:10.1016/s1535-6108(04)00115-1.

15. Hulikova, A.; Harris, A.L.; Vaughan-Jones, R.D.; Swietach, P. Regulation of intracellular pH in cancer cell lines under normoxia and hypoxia. J Cell Physiol 2013, 228, 743-752, doi:10.1002/jcp.24221.

16. Heddleston, J.M.; Li, Z.; Lathia, J.D.; Bao, S.; Hjelmeland, A.B.; Rich, J.N. Hypoxia inducible factors in cancer stem cells. Br J Cancer 2010, 102, 789-795, doi:10.1038/sj.bjc.6605551.

17. Semenza, G.L. Hydroxylation of HIF-1: oxygen sensing at the molecular level. Physiology (Bethesda) 2004, 19, 176-182, doi:10.1152/physiol.00001.2004.

18. Schofield, C.J.; Ratcliffe, P.J. Oxygen sensing by HIF hydroxylases. Nat Rev Mol Cell Biol 2004, 5, 343354, doi:10.1038/nrm1366.

19. Appelhoff, R.J.; Tian, Y.M.; Raval, R.R.; Turley, H.; Harris, A.L.; Pugh, C.W.; Ratcliffe, P.J.; Gleadle, J.M. Differential function of the prolyl hydroxylases PHD1, PHD2, and PHD3 in the regulation of hypoxiainducible factor. J Biol Chem 2004, 279, 38458-38465, doi:10.1074/jbc.M406026200.

20. Franke, K.; Kalucka, J.; Mamlouk, S.; Singh, R.P.; Muschter, A.; Weidemann, A.; Iyengar, V.; Jahn, S.; Wieczorek, K.; Geiger, K., et al. HIF-1alpha is a protective factor in conditional PHD2-deficient mice suffering from severe HIF-2alpha-induced excessive erythropoiesis. Blood 2013, 121, 1436-1445, doi:10.1182/blood-2012-08-449181.

21. Meneses, A.M.; Wielockx, B. PHD2: from hypoxia regulation to disease progression. Hypoxia (Auckl) 2016, 4, 53-67, doi:10.2147/HP.S53576.

22. Wang, G.L.; Jiang, B.H.; Rue, E.A.; Semenza, G.L. Hypoxia-inducible factor 1 is a basic-helix-loop-helixPAS heterodimer regulated by cellular O2 tension. Proc Natl Acad Sci U S A 1995, 92, 5510-5514.

23. Jaakkola, P.; Mole, D.R.; Tian, Y.M.; Wilson, M.I.; Gielbert, J.; Gaskell, S.J.; von Kriegsheim, A.; Hebestreit, H.F.; Mukherji, M.; Schofield, C.J., et al. Targeting of HIF-alpha to the von Hippel-Lindau ubiquitylation complex by O2-regulated prolyl hydroxylation. Science 2001, 292, 468-472, doi:10.1126/science.1059796.

24. Riemann, A.; Reime, S.; Thews, O. Tumor Acidosis and Hypoxia Differently Modulate the Inflammatory Program: Measurements In Vitro and In Vivo. Neoplasia 2017, 19, 1033-1042, doi:10.1016/j.neo.2017.09.005.

25. Tzamali, E.; Grekas, G.; Marias, K.; Sakkalis, V. Exploring the competition between proliferative and invasive cancer phenotypes in a continuous spatial model. PLoS One 2014, 9, e103191, doi:10.1371/journal.pone.0103191.

26. Gupta, S.; Roy, A.; Dwarakanath, B.S. Metabolic Cooperation and Competition in the Tumor Microenvironment: Implications for Therapy. Front Oncol 2017, 7, 68, doi:10.3389/fonc.2017.00068.

27. Barsoum, I.B.; Koti, M.; Siemens, D.R.; Graham, C.H. Mechanisms of hypoxia-mediated immune escape in cancer. Cancer Res 2014, 74, 7185-7190, doi:10.1158/0008-5472.CAN-14-2598.

28. Li, Y.; Patel, S.P.; Roszik, J.; Qin, Y. Hypoxia-Driven Immunosuppressive Metabolites in the Tumor Microenvironment: New Approaches for Combinational Immunotherapy. Front Immunol 2018, 9, 1591, doi:10.3389/fimmu.2018.01591.

29. Giaccia, A.J. Hypoxic Stress Proteins: Survival of the Fittest. Semin Radiat Oncol 1996, 6, 46-58, doi:10.1053/SRAO0060046.

30. Luis, R.; Brito, C.; Pojo, M. Melanoma Metabolism: Cell Survival and Resistance to Therapy. Adv Exp Med Biol 2020, 1219, 203-223, doi:10.1007/978-3-030-34025-4_11. 
31. Lugano, R.; Ramachandran, M.; Dimberg, A. Tumor angiogenesis: causes, consequences, challenges and opportunities. Cell Mol Life Sci 2020, 77, 1745-1770, doi:10.1007/s00018-019-03351-7.

32. Dunleavey, J.M.; Dudley, A.C. Vascular Mimicry: Concepts and Implications for Anti-Angiogenic Therapy. Curr Angiogenes 2012, 1, 133-138, doi:10.2174/2211552811201020133.

33. Ebos, J.M.; Lee, C.R.; Cruz-Munoz, W.; Bjarnason, G.A.; Christensen, J.G.; Kerbel, R.S. Accelerated metastasis after short-term treatment with a potent inhibitor of tumor angiogenesis. Cancer Cell 2009, 15, 232-239, doi:10.1016/j.ccr.2009.01.021.

34. Paez-Ribes, M.; Allen, E.; Hudock, J.; Takeda, T.; Okuyama, H.; Vinals, F.; Inoue, M.; Bergers, G.; Hanahan, D.; Casanovas, O. Antiangiogenic therapy elicits malignant progression of tumors to increased local invasion and distant metastasis. Cancer Cell 2009, 15, 220-231, doi:10.1016/j.ccr.2009.01.027.

35. Feng, H.; Wang, J.; Chen, W.; Shan, B.; Guo, Y.; Xu, J.; Wang, L.; Guo, P.; Zhang, Y. Hypoxia-induced autophagy as an additional mechanism in human osteosarcoma radioresistance. J Bone Oncol 2016, 5, 6773, doi:10.1016/j.jbo.2016.03.001.

36. He, W.S.; Dai, X.F.; Jin, M.; Liu, C.W.; Rent, J.H. Hypoxia-induced autophagy confers resistance of breast cancer cells to ionizing radiation. Oncol Res 2012, 20, 251-258, doi:10.3727/096504013x13589503483012.

37. Harada, H.; Inoue, M.; Itasaka, S.; Hirota, K.; Morinibu, A.; Shinomiya, K.; Zeng, L.; Ou, G.; Zhu, Y.; Yoshimura, M., et al. Cancer cells that survive radiation therapy acquire HIF-1 activity and translocate towards tumour blood vessels. Nat Commun 2012, 3, 783, doi:10.1038/ncomms1786.

38. Overgaard, J. Hypoxic radiosensitization: adored and ignored. J Clin Oncol 2007, 25, 4066-4074, doi:10.1200/JCO.2007.12.7878.

39. Zhou, M.; Hou, J.; Li, Y.; Mou, S.; Wang, Z.; Horch, R.E.; Sun, J.; Yuan, Q. The pro-angiogenic role of hypoxia inducible factor stabilizer FG-4592 and its application in an in vivo tissue engineering chamber model. Sci Rep 2019, 9, 6035, doi:10.1038/s41598-019-41924-5.

40. Azzi, S.; Hebda, J.K.; Gavard, J. Vascular permeability and drug delivery in cancers. Front Oncol 2013, 3, 211, doi:10.3389/fonc.2013.00211.

41. Wu, M.; Frieboes, H.B.; McDougall, S.R.; Chaplain, M.A.; Cristini, V.; Lowengrub, J. The effect of interstitial pressure on tumor growth: coupling with the blood and lymphatic vascular systems. J Theor Biol 2013, 320, 131-151, doi:10.1016/j.jtbi.2012.11.031.

42. Jain, R.K. Delivery of molecular medicine to solid tumors: lessons from in vivo imaging of gene expression and function. Journal of controlled release : official journal of the Controlled Release Society 2001, 74, 725, doi:10.1016/s0168-3659(01)00306-6.

43. Mazzone, M.; Dettori, D.; de Oliveira, R.L.; Loges, S.; Schmidt, T.; Jonckx, B.; Tian, Y.M.; Lanahan, A.A.; Pollard, P.; de Almodovar, C.R., et al. Heterozygous deficiency of PHD2 restores tumor oxygenation and inhibits metastasis via endothelial normalization. Cell 2009, 136, 839-851, doi:10.1016/j.cell.2009.01.020.

44. Chiche, J.; Brahimi-Horn, M.C.; Pouyssegur, J. Tumour hypoxia induces a metabolic shift causing acidosis: a common feature in cancer. J Cell Mol Med 2010, 14, 771-794, doi:10.1111/j.1582-4934.2009.00994.x.

45. Semenza, G.L. Targeting HIF-1 for cancer therapy. Nat Rev Cancer 2003, 3, 721-732, doi:10.1038/nrc1187.

46. Lee, G.; Won, H.S.; Lee, Y.M.; Choi, J.W.; Oh, T.I.; Jang, J.H.; Choi, D.K.; Lim, B.O.; Kim, Y.J.; Park, J.W., et al. Oxidative Dimerization of PHD2 is Responsible for its Inactivation and Contributes to Metabolic Reprogramming via HIF-1alpha Activation. Sci Rep 2016, 6, 18928, doi:10.1038/srep18928.

47. Munir, R.; Lisec, J.; Swinnen, J.V.; Zaidi, N. Lipid metabolism in cancer cells under metabolic stress. Br J Cancer 2019, 120, 1090-1098, doi:10.1038/s41416-019-0451-4.

48. Zhang, M.; Di Martino, J.S.; Bowman, R.L.; Campbell, N.R.; Baksh, S.C.; Simon-Vermot, T.; Kim, I.S.; Haldeman, P.; Mondal, C.; Yong-Gonzales, V., et al. Adipocyte-Derived Lipids Mediate Melanoma Progression via FATP Proteins. Cancer Discov 2018, 8, 1006-1025, doi:10.1158/2159-8290.CD-17-1371.

49. Vaupel, P.; Schmidberger, H.; Mayer, A. The Warburg effect: essential part of metabolic reprogramming and central contributor to cancer progression. Int $J$ Radiat Biol 2019, 95, 912-919, doi:10.1080/09553002.2019.1589653.

50. Gatenby, R.A.; Gillies, R.J. Why do cancers have high aerobic glycolysis? Nat Rev Cancer 2004, 4, 891899, doi:10.1038/nrc1478.

51. Stanta, G.; Bonin, S. Overview on Clinical Relevance of Intra-Tumor Heterogeneity. Front Med (Lausanne) 2018, 5, 85, doi:10.3389/fmed.2018.00085.

52. Dagogo-Jack, I.; Shaw, A.T. Tumour heterogeneity and resistance to cancer therapies. Nat Rev Clin Oncol 2018, 15, 81-94, doi:10.1038/nrclinonc.2017.166. 
53. Guido, C.; Whitaker-Menezes, D.; Capparelli, C.; Balliet, R.; Lin, Z.; Pestell, R.G.; Howell, A.; Aquila, S.; Ando, S.; Martinez-Outschoorn, U., et al. Metabolic reprogramming of cancer-associated fibroblasts by TGFbeta drives tumor growth: connecting TGF-beta signaling with "Warburg-like" cancer metabolism and Llactate production. Cell Cycle 2012, 11, 3019-3035, doi:10.4161/cc.21384.

54. Leone, R.D.; Powell, J.D. Metabolism of immune cells in cancer. Nat Rev Cancer 2020, 20, 516-531, doi:10.1038/s41568-020-0273-y.

55. Jayatilaka, H.; Tyle, P.; Chen, J.J.; Kwak, M.; Ju, J.; Kim, H.J.; Lee, J.S.H.; Wu, P.H.; Gilkes, D.M.; Fan, R., et al. Synergistic IL-6 and IL-8 paracrine signalling pathway infers a strategy to inhibit tumour cell migration. Nat Commun 2017, 8, 15584, doi:10.1038/ncomms 15584.

56. Tariq, M.; Zhang, J.; Liang, G.; Ding, L.; He, Q.; Yang, B. Macrophage Polarization: Anti-Cancer Strategies to Target Tumor-Associated Macrophage in Breast Cancer. Journal of cellular biochemistry 2017, 118, 24842501, doi:10.1002/jcb.25895.

57. Obeid, E.; Nanda, R.; Fu, Y.X.; Olopade, O.I. The role of tumor-associated macrophages in breast cancer progression (review). Int J Oncol 2013, 43, 5-12, doi:10.3892/ijo.2013.1938.

58. Murdoch, C.; Giannoudis, A.; Lewis, C.E. Mechanisms regulating the recruitment of macrophages into hypoxic areas of tumors and other ischemic tissues. Blood 2004, 104, 2224-2234, doi:10.1182/blood-200403-1109.

59. Murray, P.J.; Allen, J.E.; Biswas, S.K.; Fisher, E.A.; Gilroy, D.W.; Goerdt, S.; Gordon, S.; Hamilton, J.A.; Ivashkiv, L.B.; Lawrence, T., et al. Macrophage activation and polarization: nomenclature and experimental guidelines. Immunity 2014, 41, 14-20, doi:10.1016/j.immuni.2014.06.008.

60. Jha, A.K.; Huang, S.C.; Sergushichev, A.; Lampropoulou, V.; Ivanova, Y.; Loginicheva, E.; Chmielewski, K.; Stewart, K.M.; Ashall, J.; Everts, B., et al. Network integration of parallel metabolic and transcriptional data reveals metabolic modules that regulate macrophage polarization. Immunity 2015, 42, 419-430, doi:10.1016/j.immuni.2015.02.005.

61. Wang, C.; Zhang, S.; Liu, J.; Tian, Y.; Ma, B.; Xu, S.; Fu, Y.; Luo, Y. Secreted Pyruvate Kinase M2 Promotes Lung Cancer Metastasis through Activating the Integrin Beta1/FAK Signaling Pathway. Cell Rep 2020, 30 , 1780-1797 e1786, doi:10.1016/j.celrep.2020.01.037.

62. Arlauckas, S.P.; Garren, S.B.; Garris, C.S.; Kohler, R.H.; Oh, J.; Pittet, M.J.; Weissleder, R. Arg1 expression defines immunosuppressive subsets of tumor-associated macrophages. Theranostics 2018, 8, 5842-5854, doi:10.7150/thno.26888.

63. Takeda, N.; O'Dea, E.L.; Doedens, A.; Kim, J.W.; Weidemann, A.; Stockmann, C.; Asagiri, M.; Simon, M.C.; Hoffmann, A.; Johnson, R.S. Differential activation and antagonistic function of HIF- $\{$ alpha $\}$ isoforms in macrophages are essential for NO homeostasis. Genes Dev 2010, 24, 491-501, doi:10.1101/gad.1881410.

64. Wang, L.; Niu, Z.; Wang, X.; Li, Z.; Liu, Y.; Luo, F.; Yan, X. PHD2 exerts anti-cancer and anti-inflammatory effects in colon cancer xenografts mice via attenuating NF-kappaB activity. Life Sci 2020, 242, 117167, doi:10.1016/j.lfs.2019.117167.

65. Guentsch, A.; Beneke, A.; Swain, L.; Farhat, K.; Nagarajan, S.; Wielockx, B.; Raithatha, K.; Dudek, J.; Rehling, P.; Zieseniss, A., et al. PHD2 Is a Regulator for Glycolytic Reprogramming in Macrophages. Mol Cell Biol 2017, 37, doi:10.1128/mcb.00236-16.

66. Moses, K.; Brandau, S. Human neutrophils: Their role in cancer and relation to myeloid-derived suppressor cells. Semin Immunol 2016, 28, 187-196, doi:10.1016/j.smim.2016.03.018.

67. Singel, K.L.; Segal, B.H. Neutrophils in the tumor microenvironment: trying to heal the wound that cannot heal. Immunol Rev 2016, 273, 329-343, doi:10.1111/imr.12459.

68. Shaul, M.E.; Levy, L.; Sun, J.; Mishalian, I.; Singhal, S.; Kapoor, V.; Horng, W.; Fridlender, G.; Albelda, S.M.; Fridlender, Z.G. Tumor-associated neutrophils display a distinct N1 profile following TGFbeta modulation: A transcriptomics analysis of pro- vs. antitumor TANs. Oncoimmunology 2016, 5, e1232221, doi:10.1080/2162402X.2016.1232221.

69. Kalafati, L.; Kourtzelis, I.; Schulte-Schrepping, J.; Li, X.; Hatzioannou, A.; Grinenko, T.; Hagag, E.; Sinha, A.; Has, C.; Dietz, S., et al. Innate Immune Training of Granulopoiesis Promotes Anti-tumor Activity. Cell 2020, 183, 771-785 e712, doi:10.1016/j.cell.2020.09.058.

70. Gurusamy, D.; Clever, D.; Eil, R.; Restifo, N.P. Novel "Elements" of Immune Suppression within the Tumor Microenvironment. Cancer Immunol Res 2017, 5, 426-433, doi:10.1158/2326-6066.CIR-17-0117.

71. Dang, Eric V.; Barbi, J.; Yang, H.-Y.; Jinasena, D.; Yu, H.; Zheng, Y.; Bordman, Z.; Fu, J.; Kim, Y.; Yen, H.-R., et al. Control of TH17/Treg Balance by Hypoxia-Inducible Factor 1. Cell 2011, 146, 772-784, doi:10.1016/j.cell.2011.07.033. 
72. Chiu, D.K.; Xu, I.M.; Lai, R.K.; Tse, A.P.; Wei, L.L.; Koh, H.Y.; Li, L.L.; Lee, D.; Lo, R.C.; Wong, C.M., et al. Hypoxia induces myeloid-derived suppressor cell recruitment to hepatocellular carcinoma through chemokine (C-C motif) ligand 26. Hepatology 2016, 64, 797-813, doi:10.1002/hep.28655.

73. Groth, C.; Hu, X.; Weber, R.; Fleming, V.; Altevogt, P.; Utikal, J.; Umansky, V. Immunosuppression mediated by myeloid-derived suppressor cells (MDSCs) during tumour progression. Br J Cancer 2019, 120 , 16-25, doi:10.1038/s41416-018-0333-1.

74. Corzo, C.A.; Condamine, T.; Lu, L.; Cotter, M.J.; Youn, J.I.; Cheng, P.; Cho, H.I.; Celis, E.; Quiceno, D.G.; Padhya, T., et al. HIF-1alpha regulates function and differentiation of myeloid-derived suppressor cells in the tumor microenvironment. J Exp Med 2010, 207, 2439-2453, doi:10.1084/jem.20100587.

75. Kumar, V.; Patel, S.; Tcyganov, E.; Gabrilovich, D.I. The Nature of Myeloid-Derived Suppressor Cells in the Tumor Microenvironment. Trends Immunol 2016, 37, 208-220, doi:10.1016/j.it.2016.01.004.

76. Li, W.; Zhang, X.; Chen, Y.; Xie, Y.; Liu, J.; Feng, Q.; Wang, Y.; Yuan, W.; Ma, J. G-CSF is a key modulator of MDSC and could be a potential therapeutic target in colitis-associated colorectal cancers. Protein Cell 2016, 7, 130-140, doi:10.1007/s13238-015-0237-2.

77. Zhang, Q.Q.; Hu, X.W.; Liu, Y.L.; Ye, Z.J.; Gui, Y.H.; Zhou, D.L.; Qi, C.L.; He, X.D.; Wang, H.; Wang, L.J. CD11b deficiency suppresses intestinal tumor growth by reducing myeloid cell recruitment. Sci Rep 2015, 5, 15948, doi:10.1038/srep15948.

78. Magnuson, A.M.; Kiner, E.; Ergun, A.; Park, J.S.; Asinovski, N.; Ortiz-Lopez, A.; Kilcoyne, A.; PaoluzziTomada, E.; Weissleder, R.; Mathis, D., et al. Identification and validation of a tumor-infiltrating Treg transcriptional signature conserved across species and tumor types. Proc Natl Acad Sci U S A 2018, 115, E10672-E10681, doi:10.1073/pnas.1810580115.

79. Syed Khaja, A.S.; Toor, S.M.; El Salhat, H.; Faour, I.; Ul Haq, N.; Ali, B.R.; Elkord, E. Preferential accumulation of regulatory $\mathrm{T}$ cells with highly immunosuppressive characteristics in breast tumor microenvironment. Oncotarget 2017, 8, 33159-33171, doi:10.18632/oncotarget.16565.

80. Lin, Y.C.; Mahalingam, J.; Chiang, J.M.; Su, P.J.; Chu, Y.Y.; Lai, H.Y.; Fang, J.H.; Huang, C.T.; Chiu, C.T.; Lin, C.Y. Activated but not resting regulatory $\mathrm{T}$ cells accumulated in tumor microenvironment and correlated with tumor progression in patients with colorectal cancer. Int J Cancer 2013, 132, 1341-1350, doi:10.1002/ijc.27784.

81. Chaudhary, B.; Elkord, E. Regulatory T Cells in the Tumor Microenvironment and Cancer Progression: Role and Therapeutic Targeting. Vaccines (Basel) 2016, 4, doi:10.3390/vaccines4030028.

82. Clambey, E.T.; McNamee, E.N.; Westrich, J.A.; Glover, L.E.; Campbell, E.L.; Jedlicka, P.; de Zoeten, E.F.; Cambier, J.C.; Stenmark, K.R.; Colgan, S.P., et al. Hypoxia-inducible factor-1 alpha-dependent induction of FoxP3 drives regulatory T-cell abundance and function during inflammatory hypoxia of the mucosa. Proc Natl Acad Sci U S A 2012, 109, E2784-2793, doi:10.1073/pnas.1202366109.

83. Hori, S.; Nomura, T.; Sakaguchi, S. Control of regulatory T cell development by the transcription factor Foxp3. Science 2003, 299, 1057-1061, doi:10.1126/science.1079490.

84. Yamamoto, A.; Hester, J.; Macklin, P.S.; Kawai, K.; Uchiyama, M.; Biggs, D.; Bishop, T.; Bull, K.; Cheng, X.; Cawthorne, E., et al. Systemic silencing of Phd2 causes reversible immune regulatory dysfunction. Journal of Clinical Investigation 2019, 129, 3640-3656, doi:10.1172/jci124099.

85. Tong, W.W.; Tong, G.H.; Liu, Y. Cancer stem cells and hypoxia-inducible factors (Review). Int J Oncol 2018, 53, 469-476, doi:10.3892/ijo.2018.4417.

86. Pascual, G.; Avgustinova, A.; Mejetta, S.; Martin, M.; Castellanos, A.; Attolini, C.S.; Berenguer, A.; Prats, N.; Toll, A.; Hueto, J.A., et al. Targeting metastasis-initiating cells through the fatty acid receptor CD36. Nature 2017, 541, 41-45, doi:10.1038/nature20791.

87. Batlle, E.; Clevers, H. Cancer stem cells revisited. Nat Med 2017, 23, 1124-1134, doi:10.1038/nm.4409.

88. Sierra, H.; Cordova, M.; Chen, C.J.; Rajadhyaksha, M. Confocal imaging-guided laser ablation of basal cell carcinomas: an ex vivo study. J Invest Dermatol 2015, 135, 612-615, doi:10.1038/jid.2014.371.

89. Kim, H.; Lin, Q.; Glazer, P.M.; Yun, Z. The hypoxic tumor microenvironment in vivo selects the cancer stem cell fate of breast cancer cells. Breast cancer research : BCR 2018, 20, 16, doi:10.1186/s13058-018-0944-8.

90. Virolle, T. [Cancer stem cells in glioblastoma]. Bull Cancer 2017, 104, 1075-1079, doi:10.1016/j.bulcan.2017.10.012.

91. Murat, A.; Migliavacca, E.; Gorlia, T.; Lambiv, W.L.; Shay, T.; Hamou, M.F.; de Tribolet, N.; Regli, L.; Wick, W.; Kouwenhoven, M.C., et al. Stem cell-related "self-renewal" signature and high epidermal growth factor receptor expression associated with resistance to concomitant chemoradiotherapy in glioblastoma. $J$ Clin Oncol 2008, 26, 3015-3024, doi:10.1200/JCO.2007.15.7164. 
92. Colwell, N.; Larion, M.; Giles, A.J.; Seldomridge, A.N.; Sizdahkhani, S.; Gilbert, M.R.; Park, D.M. Hypoxia in the glioblastoma microenvironment: shaping the phenotype of cancer stem-like cells. Neuro Oncol 2017, 19, 887-896, doi:10.1093/neuonc/now258.

93. Papale, M.; Buccarelli, M.; Mollinari, C.; Russo, M.A.; Pallini, R.; Ricci-Vitiani, L.; Tafani, M. Hypoxia, Inflammation and Necrosis as Determinants of Glioblastoma Cancer Stem Cells Progression. Int J Mol Sci 2020, 21, doi:10.3390/ijms21082660.

94. Ignatova, T.N.; Kukekov, V.G.; Laywell, E.D.; Suslov, O.N.; Vrionis, F.D.; Steindler, D.A. Human cortical glial tumors contain neural stem-like cells expressing astroglial and neuronal markers in vitro. Glia 2002, 39, 193-206, doi:10.1002/glia.10094.

95. Soeda, A.; Park, M.; Lee, D.; Mintz, A.; Androutsellis-Theotokis, A.; McKay, R.D.; Engh, J.; Iwama, T.; Kunisada, T.; Kassam, A.B., et al. Hypoxia promotes expansion of the CD133-positive glioma stem cells through activation of HIF-1alpha. Oncogene 2009, 28, 3949-3959, doi:10.1038/onc.2009.252.

96. D'Alessio, A.; Proietti, G.; Lama, G.; Biamonte, F.; Lauriola, L.; Moscato, U.; Vescovi, A.; Mangiola, A.; Angelucci, C.; Sica, G. Analysis of angiogenesis related factors in glioblastoma, peritumoral tissue and their derived cancer stem cells. Oncotarget 2016, 7, 78541-78556, doi:10.18632/oncotarget.12398.

97. Li, Z.; Bao, S.; Wu, Q.; Wang, H.; Eyler, C.; Sathornsumetee, S.; Shi, Q.; Cao, Y.; Lathia, J.; McLendon, R.E., et al. Hypoxia-inducible factors regulate tumorigenic capacity of glioma stem cells. Cancer Cell $\mathbf{2 0 0 9}$, 15, 501-513, doi:10.1016/j.ccr.2009.03.018.

98. Johansson, E.; Grassi, E.S.; Pantazopoulou, V.; Tong, B.; Lindgren, D.; Berg, T.J.; Pietras, E.J.; Axelson, H.; Pietras, A. CD44 Interacts with HIF-2alpha to Modulate the Hypoxic Phenotype of Perinecrotic and Perivascular Glioma Cells. Cell Rep 2017, 20, 1641-1653, doi:10.1016/j.celrep.2017.07.049.

99. Singh, A.; Settleman, J. EMT, cancer stem cells and drug resistance: an emerging axis of evil in the war on cancer. Oncogene 2010, 29, 4741-4751, doi:10.1038/onc.2010.215.

100. Chaffer, C.L.; San Juan, B.P.; Lim, E.; Weinberg, R.A. EMT, cell plasticity and metastasis. Cancer Metastasis Rev 2016, 35, 645-654, doi:10.1007/s10555-016-9648-7.

101. Mani, S.A.; Guo, W.; Liao, M.J.; Eaton, E.N.; Ayyanan, A.; Zhou, A.Y.; Brooks, M.; Reinhard, F.; Zhang, C.C.; Shipitsin, M., et al. The epithelial-mesenchymal transition generates cells with properties of stem cells. Cell 2008, 133, 704-715, doi:10.1016/j.cell.2008.03.027.

102. Yang, M.H.; Wu, K.J. TWIST activation by hypoxia inducible factor-1 (HIF-1): implications in metastasis and development. Cell Cycle 2008, 7, 2090-2096, doi:10.4161/cc.7.14.6324.

103. Zhu, J.; Huang, Z.; Zhang, M.; Wang, W.; Liang, H.; Zeng, J.; Wu, K.; Wang, X.; Hsieh, J.T.; Guo, P., et al. HIF-1alpha promotes ZEB1 expression and EMT in a human bladder cancer lung metastasis animal model. Oncol Lett 2018, 15, 3482-3489, doi:10.3892/ol.2018.7764.

104. Zhang, W.J.; Shi, X.P.; Peng, Y.; Wu, M.Y.; Zhang, P.; Xie, R.Y.; Wu, Y.; Yan, Q.Q.; Liu, S.D.; Wang, J.D. HIF-1 alpha Promotes Epithelial-Mesenchymal Transition and Metastasis through Direct Regulation of ZEB1 in Colorectal Cancer. Plos One 2015, 10, doi:ARTN e0129603

10.1371/journal.pone.0129603.

105. Yang, M.H.; Wu, M.Z.; Chiou, S.H.; Chen, P.M.; Chang, S.Y.; Liu, C.J.; Teng, S.C.; Wu, K.J. Direct regulation of TWIST by HIF-1alpha promotes metastasis. Nat Cell Biol 2008, 10, 295-305, doi:10.1038/ncb1691.

106. Evans, A.J.; Russell, R.C.; Roche, O.; Burry, T.N.; Fish, J.E.; Chow, V.W.K.; Kim, W.Y.; Saravanan, A.; Maynard, M.A.; Gervais, M.L., et al. VHL promotes E2 box-dependent E-cadherin transcription by HIFmediated regulation of SIP1 and snail. Molecular and Cellular Biology 2007, 27, 157-169, doi:10.1128/Mcb.00892-06.

107. Lin, C.W.; Wang, L.K.; Wang, S.P.; Chang, Y.L.; Wu, Y.Y.; Chen, H.Y.; Hsiao, T.H.; Lai, W.Y.; Lu, H.H.; Chang, Y.H., et al. Daxx inhibits hypoxia-induced lung cancer cell metastasis by suppressing the HIF-1 alpha/HDAC1/Slug axis. Nature Communications 2016, 7, doi:ARTN 13867

10.1038/ncomms13867.

108. Lin, C.C.; Cheng, T.L.; Tsai, W.H.; Tsai, H.J.; Hu, K.H.; Chang, H.C.; Yeh, C.W.; Chen, Y.C.; Liao, C.C.; Chang, W.T. Loss of the respiratory enzyme citrate synthase directly links the Warburg effect to tumor malignancy. Sci Rep 2012, 2, 785, doi:10.1038/srep00785. 
109. Kuzmanov, A.; Wielockx, B.; Rezaei, M.; Kettelhake, A.; Breier, G. Overexpression of factor inhibiting HIF1 enhances vessel maturation and tumor growth via platelet-derived growth factor-C. International Journal of Cancer 2012, 131, E603-E613, doi:10.1002/ijc.27360.

110. Cho, K.H.; Choi, M.J.; Jeong, K.J.; Kim, J.J.; Hwang, M.H.; Shin, S.C.; Park, C.G.; Lee, H.Y. A ROS/STAT3/HIF-1alpha signaling cascade mediates EGF-induced TWIST1 expression and prostate cancer cell invasion. Prostate 2014, 74, 528-536, doi:10.1002/pros.22776.

111. Li, H.; Rokavec, M.; Jiang, L.; Horst, D.; Hermeking, H. Antagonistic Effects of p53 and HIF1A on microRNA-34a Regulation of PPP1R11 and STAT3 and Hypoxia-induced Epithelial to Mesenchymal Transition in Colorectal Cancer Cells. Gastroenterology 2017, 153, 505-520, doi:10.1053/j.gastro.2017.04.017.

112. Bao, B.; Azmi, A.S.; Ali, S.; Ahmad, A.; Li, Y.; Banerjee, S.; Kong, D.; Sarkar, F.H. The biological kinship of hypoxia with CSC and EMT and their relationship with deregulated expression of miRNAs and tumor aggressiveness. Biochim Biophys Acta 2012, 1826, 272-296, doi:10.1016/j.bbcan.2012.04.008.

113. Serocki, M.; Bartoszewska, S.; Janaszak-Jasiecka, A.; Ochocka, R.J.; Collawn, J.F.; Bartoszewski, R. miRNAs regulate the HIF switch during hypoxia: a novel therapeutic target. Angiogenesis 2018, 21, 183202, doi:10.1007/s10456-018-9600-2.

114. Hong, D.S.; Kang, Y.K.; Borad, M.; Sachdev, J.; Ejadi, S.; Lim, H.Y.; Brenner, A.J.; Park, K.; Lee, J.L.; Kim, T.Y., et al. Phase 1 study of MRX34, a liposomal miR-34a mimic, in patients with advanced solid tumours. Br J Cancer 2020, 122, 1630-1637, doi:10.1038/s41416-020-0802-1.

115. Yeo, C.D.; Kang, N.; Choi, S.Y.; Kim, B.N.; Park, C.K.; Kim, J.W.; Kim, Y.K.; Kim, S.J. The role of hypoxia on the acquisition of epithelial-mesenchymal transition and cancer stemness: a possible link to epigenetic regulation. Korean J Intern Med 2017, 32, 589-599, doi:10.3904/kjim.2016.302.

116. Yang, X.G.; Zhu, L.C.; Wang, Y.J.; Li, Y.Y.; Wang, D. Current Advance of Therapeutic Agents in Clinical Trials Potentially Targeting Tumor Plasticity. Frontiers in Oncology 2019, 9, doi:ARTN 887

10.3389/fonc. 2019.00887 .

117. Dahia, P.L. Pheochromocytoma and paraganglioma pathogenesis: learning from genetic heterogeneity. Nat Rev Cancer 2014, 14, 108-119, doi:10.1038/nrc3648.

118. Alrezk, R.; Suarez, A.; Tena, I.; Pacak, K. Update of Pheochromocytoma Syndromes: Genetics, Biochemical Evaluation, and Imaging. Frontiers in Endocrinology 2018, 9, doi:10.3389/fendo.2018.00515.

119. Amorim-Pires, D.; Peixoto, J.; Lima, J. Hypoxia Pathway Mutations in Pheochromocytomas and Paragangliomas. Cytogenet Genome Res 2016, 150, 227-241, doi:10.1159/000457479.

120. Fishbein, L.; Leshchiner, I.; Walter, V.; Danilova, L.; Robertson, A.G.; Johnson, A.R.; Lichtenberg, T.M.; Murray, B.A.; Ghayee, H.K.; Else, T., et al. Comprehensive Molecular Characterization of Pheochromocytoma and Paraganglioma. Cancer Cell 2017, 31, 181-193, doi:10.1016/j.ccell.2017.01.001.

121. Berends, A.M.A.; Eisenhofer, G.; Fishbein, L.; Horst-Schrivers, A.; Kema, I.P.; Links, T.P.; Lenders, J.W.M.; Kerstens, M.N. Intricacies of the Molecular Machinery of Catecholamine Biosynthesis and Secretion by Chromaffin Cells of the Normal Adrenal Medulla and in Pheochromocytoma and Paraganglioma. Cancers (Basel) 2019, 11, doi:10.3390/cancers11081121.

122. Vogel, T.W.; Brouwers, F.M.; Lubensky, I.A.; Vortmeyer, A.O.; Weil, R.J.; Walther, M.M.; Oldfield, E.H.; Linehan, W.M.; Pacak, K.; Zhuang, Z. Differential expression of erythropoietin and its receptor in von hippel-lindau-associated and multiple endocrine neoplasia type 2-associated pheochromocytomas. $J$ Clin Endocrinol Metab 2005, 90, 3747-3751, doi:10.1210/jc.2004-1899.

123. Lorenzo, F.R.; Yang, C.; Ng Tang Fui, M.; Vankayalapati, H.; Zhuang, Z.; Huynh, T.; Grossmann, M.; Pacak, K.; Prchal, J.T. A novel EPAS1/HIF2A germline mutation in a congenital polycythemia with paraganglioma. Journal of molecular medicine 2013, 91, 507-512, doi:10.1007/s00109-012-0967-z.

124. Zhuang, Z.; Yang, C.; Lorenzo, F.; Merino, M.; Fojo, T.; Kebebew, E.; Popovic, V.; Stratakis, C.A.; Prchal, J.T.; Pacak, K. Somatic HIF2A gain-of-function mutations in paraganglioma with polycythemia. $N$ Engl J Med 2012, 367, 922-930, doi:10.1056/NEJMoa1205119.

125. Favier, J.; Briere, J.J.; Burnichon, N.; Riviere, J.; Vescovo, L.; Benit, P.; Giscos-Douriez, I.; De Reynies, A.; Bertherat, J.; Badoual, C., et al. The Warburg effect is genetically determined in inherited pheochromocytomas. PLoS One 2009, 4, e7094, doi:10.1371/journal.pone.0007094.

126. Tsang, V.H.; Dwight, T.; Benn, D.E.; Meyer-Rochow, G.Y.; Gill, A.J.; Sywak, M.; Sidhu, S.; Veivers, D.; Sue, C.M.; Robinson, B.G., et al. Overexpression of miR-210 is associated with SDH-related 
pheochromocytomas, paragangliomas, and gastrointestinal stromal tumours. Endocr Relat Cancer 2014, 21, 415-426, doi:10.1530/ERC-13-0519.

127. Chen, W.; Hill, H.; Christie, A.; Kim, M.S.; Holloman, E.; Pavia-Jimenez, A.; Homayoun, F.; Ma, Y.; Patel, N.; Yell, P., et al. Targeting renal cell carcinoma with a HIF-2 antagonist. Nature 2016, 539, 112-117, doi:10.1038/nature19796.

128. Toledo, R.; Jimenez, C. Recent advances in the management of malignant pheochromocytoma and paraganglioma: focus on tyrosine kinase and hypoxia-inducible factor inhibitors. F1000Res 2018, 7 , doi:10.12688/f1000research.13995.1.

129. Scriba, L.D.; Bornstein, S.R.; Santambrogio, A.; Mueller, G.; Huebner, A.; Hauer, J.; Schedl, A.; Wielockx, B.; Eisenhofer, G.; Andoniadou, C.L., et al. Cancer Stem Cells in Pheochromocytoma and Paraganglioma. Front Endocrinol (Lausanne) 2020, 11, 79, doi:10.3389/fendo.2020.00079.

130. Oudijk, L.; Neuhofer, C.M.; Lichtenauer, U.D.; Papathomas, T.G.; Korpershoek, E.; Stoop, H.; Oosterhuis, J.W.; Smid, M.; Restuccia, D.F.; Robledo, M., et al. Immunohistochemical expression of stem cell markers in pheochromocytomas/paragangliomas is associated with SDHx mutations. European journal of endocrinology / European Federation of Endocrine Societies 2015, 173, 43-52, doi:10.1530/EJE-14-1164.

131. Templeton, A.K.; Miyamoto, S.; Babu, A.; Munshi, A.; Ramesh, R. Cancer stem cells: progress and challenges in lung cancer. Stem Cell Investig 2014, 1, 9, doi:10.3978/j.issn.2306-9759.2014.03.06.

132. Klotzsche-von Ameln, A.; Muschter, A.; Mamlouk, S.; Kalucka, J.; Prade, I.; Franke, K.; Rezaei, M.; Poitz, D.M.; Breier, G.; Wielockx, B. Inhibition of HIF prolyl hydroxylase-2 blocks tumor growth in mice through the antiproliferative activity of TGFbeta. Cancer Res 2011, 71, 3306-3316, doi:10.1158/0008-5472.CAN10-3838.

133. Di Conza, G.; Trusso Cafarello, S.; Loroch, S.; Mennerich, D.; Deschoemaeker, S.; Di Matteo, M.; Ehling, M.; Gevaert, K.; Prenen, H.; Zahedi, R.P., et al. The mTOR and PP2A Pathways Regulate PHD2 Phosphorylation to Fine-Tune HIF1alpha Levels and Colorectal Cancer Cell Survival under Hypoxia. Cell Rep 2017, 18, 1699-1712, doi:10.1016/j.celrep.2017.01.051.

134. Di Conza, G.; Trusso Cafarello, S.; Zheng, X.; Zhang, Q.; Mazzone, M. PHD2 Targeting Overcomes Breast Cancer Cell Death upon Glucose Starvation in a PP2A/B55alpha-Mediated Manner. Cell Rep 2017, 18, 28362844, doi:10.1016/j.celrep.2017.02.081.

135. Klotzsche-von Ameln, A.; Muschter, A.; Heimesaat, M.M.; Breier, G.; Wielockx, B. HIF prolyl hydroxylase2 inhibition diminishes tumor growth through matrix metalloproteinase-induced TGFbeta activation. Cancer Biol Ther 2012, 13, 216-223, doi:10.4161/cbt.13.4.18830.

136. Kozlova, N.; Wottawa, M.; Katschinski, D.M.; Kristiansen, G.; Kietzmann, T. Hypoxia-inducible factor prolyl hydroxylase 2 (PHD2) is a direct regulator of epidermal growth factor receptor (EGFR) signaling in breast cancer. Oncotarget 2017, 8, 9885-9898, doi:10.18632/oncotarget.14241.

137. Kozlova, N.; Mennerich, D.; Samoylenko, A.; Dimova, E.Y.; Koivunen, P.; Biterova, E.; Richter, K.; Hassinen, A.; Kellokumpu, S.; Manninen, A., et al. The Pro-Oncogenic Adaptor CIN85 Acts as an Inhibitory Binding Partner of Hypoxia-Inducible Factor Prolyl Hydroxylase 2. Cancer Res 2019, 79, 4042-4056, doi:10.1158/0008-5472.CAN-18-3852.

138. Vidimar, V.; Licona, C.; Ceron-Camacho, R.; Guerin, E.; Coliat, P.; Venkatasamy, A.; Ali, M.; Guenot, D.; Le Lagadec, R.; Jung, A.C., et al. A redox ruthenium compound directly targets PHD2 and inhibits the HIF1 pathway to reduce tumor angiogenesis independently of p53. Cancer Lett 2019, 440-441, 145-155, doi:10.1016/j.canlet.2018.09.029.

139. Koyama, S.; Matsunaga, S.; Imanishi, M.; Maekawa, Y.; Kitano, H.; Takeuchi, H.; Tomita, S. Tumour blood vessel normalisation by prolyl hydroxylase inhibitor repaired sensitivity to chemotherapy in a tumour mouse model. Sci Rep 2017, 7, 45621, doi:10.1038/srep45621.

140. Dopeso, H.; Jiao, H.K.; Cuesta, A.M.; Henze, A.T.; Jurida, L.; Kracht, M.; Acker-Palmer, A.; Garvalov, B.K.; Acker, T. PHD3 Controls Lung Cancer Metastasis and Resistance to EGFR Inhibitors through TGFalpha. Cancer Res 2018, 78, 1805-1819, doi:10.1158/0008-5472.CAN-17-1346.

141. Xia, Y.J.; Jiang, X.T.; Jiang, S.B.; He, X.J.; Luo, J.G.; Liu, Z.C.; Wang, L.; Tao, H.Q.; Chen, J.Z. PHD3 affects gastric cancer progression by negatively regulating HIF1A. Mol Med Rep 2017, 16, 6882-6889, doi:10.3892/mmr.2017.7455.

142. Egners, A.; Rezaei, M.; Kuzmanov, A.; Poitz, D.M.; Streichert, D.; Muller-Reichert, T.; Wielockx, B.; Breier, G. PHD3 Acts as Tumor Suppressor in Mouse Osteosarcoma and Influences Tumor Vascularization via PDGF-C Signaling. Cancers (Basel) 2018, 10, doi:10.3390/cancers10120496. 
143. Dumbrava, E.I.; Meric-Bernstam, F. Personalized cancer therapy-leveraging a knowledge base for clinical decision-making. Cold Spring Harb Mol Case Stud 2018, 4, doi:10.1101/mcs.a001578.

144. Gupta, N.; Wish, J.B. Hypoxia-Inducible Factor Prolyl Hydroxylase Inhibitors: A Potential New Treatment for Anemia in Patients With CKD. American journal of kidney diseases : the official journal of the National Kidney Foundation 2017, 69, 815-826, doi:10.1053/j.ajkd.2016.12.011.

145. Yeh, T.L.; Leissing, T.M.; Abboud, M.I.; Thinnes, C.C.; Atasoylu, O.; Holt-Martyn, J.P.; Zhang, D.; Tumber, A.; Lippl, K.; Lohans, C.T., et al. Molecular and cellular mechanisms of HIF prolyl hydroxylase inhibitors in clinical trials. Chem Sci 2017, 8, 7651-7668, doi:10.1039/c7sc02103h.

146. Nishide, S.; Uchida, J.; Matsunaga, S.; Tokudome, K.; Yamaguchi, T.; Kabei, K.; Moriya, T.; Miura, K.; Nakatani, T.; Tomita, S. Prolyl-hydroxylase inhibitors reconstitute tumor blood vessels in mice. J Pharmacol Sci 2020, 143, 122-126, doi:10.1016/j.jphs.2020.02.010.

147. SHALWITZ, R. Compounds and compositions for stabilizing hypoxia inducible factor-2 alpha as a method for treating cancer. 2012.

148. Nishide, S.; Matsunaga, S.; Shiota, M.; Yamaguchi, T.; Kitajima, S.; Maekawa, Y.; Takeda, N.; Tomura, M.; Uchida, J.; Miura, K., et al. Controlling the Phenotype of Tumor-Infiltrating Macrophages via the PHD-HIF Axis Inhibits Tumor Growth in a Mouse Model. iScience 2019, 21, 205, doi:10.1016/j.isci.2019.10.031.

149. Pergola, P.E.; Spinowitz, B.S.; Hartman, C.S.; Maroni, B.J.; Haase, V.H. Vadadustat, a novel oral HIF stabilizer, provides effective anemia treatment in nondialysis-dependent chronic kidney disease. Kidney International 2016, 90, 1115-1122, doi:10.1016/j.kint.2016.07.019.

150. Adams, D.F.; Watkins, M.S.; Durette, L.; Laliberte, J.; Goulet, F.; Debien, E.; Frazier, K.S.; Mellal, N.; Chen, L.; Shi, W., et al. Carcinogenicity Assessment of Daprodustat (GSK1278863), a Hypoxia-Inducible Factor (HIF)-Prolyl Hydroxylase Inhibitor. Toxicol Pathol 2020, 48, 362-378, doi:10.1177/0192623319880445.

151. Kachamakova-Trojanowska, N.; Podkalicka, P.; Bogacz, T.; Barwacz, S.; Jozkowicz, A.; Dulak, J.; Loboda, A. HIF-1 stabilization exerts anticancer effects in breast cancer cells in vitro and in vivo. Biochemical pharmacology 2020, 175, 113922, doi:10.1016/j.bcp.2020.113922.

152. Seeley, T.W.; Sternlicht, M.D.; Klaus, S.J.; Neff, T.B.; Liu, D.Y. Induction of erythropoiesis by hypoxiainducible factor prolyl hydroxylase inhibitors without promotion of tumor initiation, progression, or metastasis in a VEGF-sensitive model of spontaneous breast cancer. Hypoxia (Auckl) 2017, 5, 1-9, doi:10.2147/HP.S130526.

153. Haase, V.H. Got glycogen? An energy resource in HIF-mediated prevention of ischemic kidney injury. Kidney Int 2020, 97, 645-647, doi:10.1016/j.kint.2019.11.036.

154. Zois, C.E.; Harris, A.L. Glycogen metabolism has a key role in the cancer microenvironment and provides new targets for cancer therapy. Journal of molecular medicine 2016, 94, 137-154, doi:10.1007/s00109-0151377-9.

155. Semenza, G.L. Oxygen sensing, hypoxia-inducible factors, and disease pathophysiology. Annu Rev Pathol 2014, 9, 47-71, doi:10.1146/annurev-pathol-012513-104720.

156. Ariazi, J.L.; Duffy, K.J.; Adams, D.F.; Fitch, D.M.; Luo, L.; Pappalardi, M.; Biju, M.; DiFilippo, E.H.; Shaw, T.; Wiggall, K., et al. Discovery and Preclinical Characterization of GSK1278863 (Daprodustat), a Small Molecule Hypoxia Inducible Factor-Prolyl Hydroxylase Inhibitor for Anemia. J Pharmacol Exp Ther 2017, 363, 336-347, doi:10.1124/jpet.117.242503.

157. Beck, H.; Jeske, M.; Thede, K.; Stoll, F.; Flamme, I.; Akbaba, M.; Erguden, J.K.; Karig, G.; Keldenich, J.; Oehme, F., et al. Discovery of Molidustat (BAY 85-3934): A Small-Molecule Oral HIF-Prolyl Hydroxylase (HIF-PH) Inhibitor for the Treatment of Renal Anemia. ChemMedChem 2018, 13, 988-1003, doi:10.1002/cmdc.201700783.

158. Sanchez-Rovira, P.; Jaen, A.; Gonzalez, E.; Porras, I.; Duenas, M.R.; Medina, B.; Mohedano, N.; Fernandez, M.; Martos, M.; Lozano, A. Phase II trial of gemcitabine/doxorubicin/paclitaxel administered every other week in patients with metastatic breast cancer. Clin Breast Cancer 2000, 1, 226-232, doi:10.3816/CBC.2000.n.019. 